\title{
Investigación de los atractivos turísticos a partir del análisis del turismo histórico - San Cristóbal, Islas Galápagos - Ecuador
}

\section{Research on tourist attractions and products based on the analysis of historical tourism - San Cristobal, Galapagos}

1 Angie Juliana Liviapoma Álvarez

Universidad Técnica de Ambato, Facultad de Ciencias Humanas y de la Educación,

Carrera de Turismo y Hotelería. San Cristóbal, Ecuador.

aliviapoma5789@uta.edu.ec

2 Rommel Santiago Velastegui Hernández

Universidad Técnica de Ambato, Facultad de Ciencias de la Educación, Carrera de Turismo. Ambato, Ecuador.

rs.velastegui@uta.edu.ec

3 Daniel Oswaldo Sánchez Guerrero

Universidad Técnica de Ambato, Facultad de Ciencias de la Educación, Carrera de Turismo. Ambato, Ecuador.

do.sanchez@uta.edu.ec

4 Sonia Paola Armas Arias

Universidad Técnica de Ambato, Facultad de Ciencias de la Educación, Carrera de

Turismo. Ambato, Ecuador.

sp.armas@uta.edu.ec

\section{Artículo de Investigación Científica y Tecnológica}

Enviado: 24/12/2021

Revisado: $29 / 12 / 2021$

Aceptado: $12 / 01 / 2022$

Publicado:08/03/2023

DOI: https://doi.org/10.33262/concienciadigital.v6i1.4.2004

Liviapoma Álvarez, A. J., Velastegui Hernández, R. S., Sánchez Guerrero, D. O., \& Armas Arias, S. P. (2023). Investigación de los atractivos turísticos a partir del análisis del turismo histórico - San Cristóbal, Islas Galápagos - Ecuador. ConcienciaDigital, 6(1.4), 390-403. https://doi.org/10.33262/concienciadigital.v6i1.4.2004

CONCIENCIA DIGITAL, es una Revista Multidisciplinar, Trimestral, que se publicará en soporte electrónico tiene como misión contribuir a la formación de profesionales competentes con visión humanística y crítica que sean capaces de exponer sus resultados investigativos y científicos en la misma medida que se promueva mediante su intervención cambios positivos en la sociedad. https://concienciadigital.org

La revista es editada por la Editorial Ciencia Digital (Editorial de prestigio registrada en la Cámara Ecuatoriana de Libro con No de Afiliación 663) www.celibro.org.ec 
Palabras

claves:

turismo

histórico, atractivos, producto turístico, itinerario, recursos

\section{Keywords:}

historical tourism, attractions, tourist product, itinerary, resources.

\section{Resumen}

La presente investigación propone analizar los atractivos y recursos turísticos que posee el Cantón San Cristóbal, inicialmente se hace un diagnóstico de los atractivos turísticos utilizando fuentes bibliográficas provistas por la institución rectora; Posteriormente, define el estado actual de los atractivos turísticos históricos, definió la cantidad de atractivos existentes y las posibles actividades turísticas que se pueden realizar con ellos, se identificaron cuatro puntos más relevantes: (i) Casa Manuel Julián Cobos, (ii) Reliquias del Ingenio Manuel J. Cobos, (iii) Casa de los Trabajadores, (iv) Tumba de Manuel J. Cobos; Estos puntos, por su ubicación geográfica y sus características patrimoniales únicas, son de gran relevancia para la historia de la colonización de las Islas Galápagos del Ecuador. Con el descubrimiento y luego de cumplir con ciertas recomendaciones técnicas del MINTUR, estos atractivos pueden generar fuentes de empleo e ingresos para una economía sostenible para los habitantes de la localidad, ya que tienen un valor patrimonial incomparable y generan la atención e interés de los residentes y aún más. de turistas nacionales y extranjeros.

\section{Abstract}

This research proposes to analyze the tourist attractions and resources that the San Cristóbal Canton has, initially a diagnosis of the tourist attractions is made using bibliographic sources provided by the governing institution; Subsequently, it defines the current state of the historical tourist attractions, defined the number of existing attractions and the possible tourist activities that can be carried out with them, four more relevant points were identified: (i) Casa Manuel Julián Cobos, (ii) Reliquial del Ingenio Manuel J. Cobos, (iii) Casa de los Trabajadores, (iv) Tumba de Manuel J. Cobos; These points, due to their geographical location and their unique heritage characteristics, are of great relevance to the history of the colonization of the Galapagos Islands of Ecuador. With the discovery and after complying with certain technical recommendations of the MINTUR, these attractions can generate sources of employment and income for a sustainable economy for the inhabitants of the town, since they have an incomparable heritage value and generate the attention and interest of the residents. and even more. of national and foreign tourists. 


\section{Introducción}

Ecuador es un país privilegiado por contar con cuatro regiones como: Amazonia, Sierra, Costa e Insular; gracias a esto cuenta con diversos atractivos: (i) naturales, (ii) culturales, lo que motiva a los turistas a conocer nuestro país, esto es notorio debido al incremento de visitantes. La Provincia de Galápagos es un sitio único que se destaca a escala mundial por su espectacular naturaleza, por este motivo proporciona datos relevantes que permitan potenciar el turismo de forma responsable en el marco de la protección y conservación de este destino de Ecuador. Ministerio de Turismo (MINTUR, 2019).

La Isla San Cristóbal tiene un gran impacto para los visitantes, ya que ofrece una maravillosa mezcla de sitios para explorar y actividades para disfrutar. Playas vírgenes e islotes rocosos se combinan con tierras altas fértiles y exuberantes para proporcionar una amplia gama de hábitats para la vida silvestre de las Galápagos. San Cristóbal es una de las pocas islas de la Provincia de Galápagos habitadas, emergió del mar hace dos puntos cuatro millones de años, lo que la convierte en una de las islas más antiguas del Archipiélago, sumado que es una gran isla para incluir en los itinerarios de excursiones terrestres y también se incluye en los cruceros (Jared, 2015).

\section{Figura 1}

Mapa de la Isla San Cristóbal

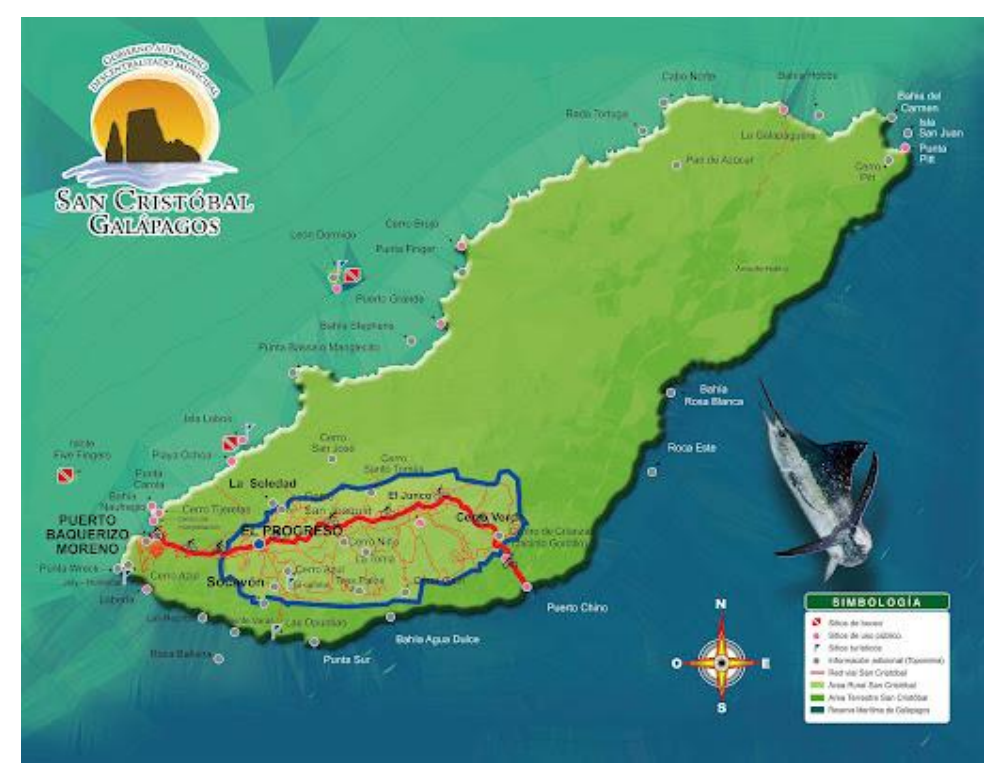

Fuente: (Gobierno Autónomo Descentralizado Municipal Gad Municipal San Cristóbal, 2015) Nota: El gráfico representa el mapa de la Isla San Cristóbal y sus principales puntos de visita.

La presencia de los viajeros en el cantón San Cristóbal son frecuentes durante todo el año; muchas personas escogen lugares con atributos naturales como las playas para vacacionar más sin embargo casi nunca optan por visitar lugares con fines culturales o históricos, 
donde se puede encontrar atributos representativos llenos de historia y simbolismo de los ancestros de años atrás en el cantón. Realizar una evaluación al atractivo turístico histórico permitiría definir el estado de este, poder referenciar parámetros o indicadores para diseñar un instrumento como herramienta para evaluarlo y a su vez proponer estrategias funcionales que permita su estado y conservación.

El turismo es una de las actividades más trascendentales para la economía de una localidad por su gran eficacia y amplitud de desarrollo. En la actualidad a los turistas les interesa vivir experiencias extraordinarias, conforme a sus actuales gustos, necesidades y prioridades, como interactuar con comunidades que visitan, interaccionarse con la naturaleza, desarrollar actividades de físicas, preservar su salud, efectuar actividades al aire libre (Morillo, 2010).

Los atractivos turísticos son considerados como la base del desarrollo turístico de una localidad, debido a que el turismo es esencial para el desarrollo de una localidad, es importante invertir en ellos para fortalecer el patrimonio, la identidad cultural, conservarlos y de igual forma motivar a los turistas para que realicen una visita (Carvajal \& Lemoine, 2017).

La existencia de atractivos turísticos históricos en el cantón San Cristóbal podría permitir generar la creación de un nuevo producto turístico para turistas residentes, nacionales o extranjeros, sin ignorar que estos nuevos productos generarían nuevas fuentes de empleo y desarrollo económico en el cantón.

Los productos turísticos se caracterizan por ser un conjunto de elementos tangibles e intangibles, que permiten el desarrollo de actividades específicas en determinados destinos; el turista compra la combinación de paquetes turísticos que incluya no solamente los atractivos de interés para él, sino también aquellas actividades que son complementarias en el país o región que pretende conocer (Nasimba \& Cejas, 2018).

El problema tiene lugar en el cantón san Cristóbal, provincia de Galápagos; en los últimos años se ha ido desarrollando el turismo en el sector, pero mucho más bajo a comparación de años anteriores por problemas de pandemia COVID-19 y demás, por lo que se ha visto necesario el desarrollo y creación de nuevos productos turísticos que contribuyan al crecimiento de la economía local que son de mayor importancia para el mercado turístico del país, a partir de un análisis del turismo histórico que contiene e cantón San Cristóbal. Con el análisis de esta investigación se brindará a los turistas y demás visitantes una alternativa u opción de visita más durante su estadía.

\section{Metodología}

La investigación de los atractivos turísticos a partir del análisis del turismo histórico - San Cristóbal, Islas Galápagos - Ecuador, plantea la siguiente metodología que consta de 
cinco pasos: (a) Inventario de atractivos turísticos San Cristóbal, Galápagos (b) Clasificación de atractivos turísticos San Cristóbal, Galápago (c) Producto Turístico; y, (d) Los itinerarios como producto Turístico (e) Atractivos turísticos de San Cristóbal.

a. Inventario de atractivos turísticos San Cristóbal, Galápagos

Tabla 1

Etapa I de realización de inventario de atractivos turísticos

\begin{tabular}{|c|c|c|c|}
\hline \multicolumn{4}{|c|}{$\begin{array}{c}\text { ETAPA I } \\
\text { Realización del inventario de atractivos turísticos }\end{array}$} \\
\hline $\begin{array}{l}\text { Fase I: Levantamiento } \\
\text { registro }\end{array}$ & $\mathrm{y}$ & $\begin{array}{l}\text { Fase II: Ponderación y } \\
\text { Jerarquización }\end{array}$ & $\begin{array}{l}\text { Fase III: Sistematización } \\
\text { geográfica de las fichas }\end{array}$ \\
\hline Obligatorio GAD & & Obligatorio GAD & Matriz MINTUR \\
\hline $\begin{array}{ll}\text { - } & \text { Clasificación } \\
\text { - } & \text { Levantamiento de } \\
\text { información primaria. } \\
\text { - } \\
\text { Verificación con } \\
\text { información secundaria }\end{array}$ & & 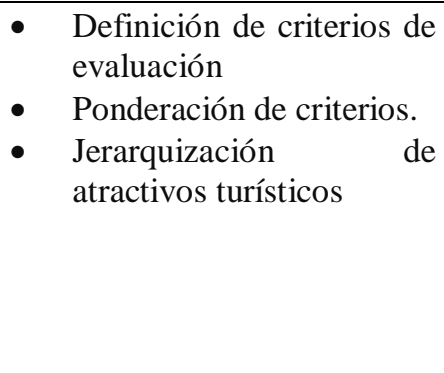 & $\begin{array}{l}\text { - } \text { Selección de atributos } \\
\text { - Conversión de Base Dato } \\
\text { (DB) a Base de Daros } \\
\text { Geográfica } \\
\text { - Categorización de } \\
\text { atractivos según catálogo } \\
\text { nacional. } \\
\text { Generación del Mapa de } \\
\text { atractivos turísticos }\end{array}$ \\
\hline
\end{tabular}

Fuente: (MINTUR, 2017)

Tabla 2

Etapa II de realización de inventario de atractivos turísticos

\section{ETAPA II}

Generación de espacios turísticos

\begin{tabular}{ll}
\hline Fase I: Identificación de Atractivos & $\begin{array}{l}\text { Fase II: Tipificación de espacios } \\
\text { turísticos }\end{array}$ \\
\hline Opcional GAD & Opcional GAD \\
\hline & $\bullet$ Especialización de información base \\
Identificación y Asociatividad de los & y temática. \\
atractivos Turísticos & - Análisis geográfico \\
& $\bullet \quad$ Tipificación de espacios turísticos \\
\hline
\end{tabular}

Fuente: (MINTUR, 2017)

Para conocer un atractivo turístico es necesario disponer de un instrumento técnico que permita orientar y normar la elaboración del inventario de atractivos turísticos históricos, las tablas 1 y 2 indican criterios para la generación de Espacios Turísticos en el territorio nacional para el desarrollo y gestión del sector, ofrece información técnica sobre la situación real de los atractivos inventariados para uso del sector público, privado, comunitario y académico y dispone de un instrumento efectivo para la generación de planes, programas y proyectos en materia turística (MINTUR, 2017). 


\section{b. Clasificación de atractivos turísticos San Cristóbal, Galápagos}

\section{Recursos Turísticos Naturales}

\section{Características generales:}

1. Son permanentes, pero requieren de prácticas de conservación

2. Son los más difíciles de reconocer:

- Por estar ubicados en lugares de difícil acceso.

- Por no existir el interés oficial en descubrirlos.

3. Su aprovechamiento en algunas circunstancias requiere modificaciones que no lo alteren básicamente.

4. Su aprovechamiento implica rodearlos de un cuadro de servicios, condición indispensable para que surja la actividad económica.

\section{Recursos Turísticos Culturales}

\section{Características generales:}

1. Son permanentes requiriendo de prácticas de restauración y conservación.

2. Son fáciles de reconocer, generalmente los estudian organismos oficiales.

3. Existe una tendencia a inventariarlos y protegerlos, pero se carece de presupuestos adecuados.

4. Su aprovechamiento requiere principalmente de campañas publicitarias que muevan el turismo hacia ellos.

5. Un alto porcentaje cuenta ya con algunos servicios, por lo que sólo es necesario complementarlos una vez que surja la actividad económica en torno a ellos (García Silberman, 2017).

\section{c. Producto Turístico}

Producto turístico es la combinación de prestaciones y elementos tangibles y no tangibles ofrecidos para satisfacer las expectativas de los turistas, otorgándoles beneficios y satisfacción de manera integral. Se distinguen dos niveles:

1. Producto turístico global o integral: está formado por los atractivos de la zona, sus infraestructuras, etc.

2. Producto turístico a nivel empresarial: es el conjunto de componentes ofrecido por las distintas empresas turísticas a sus clientes. Centro Europeo de Postgrado, la Escuela Internacional de Negocios con mayor reconocimiento de Europa (CEUPE, 2021).

Funciones básicas de un producto turístico 
Teniendo en cuenta que la satisfacción de las necesidades y expectativas del cliente es posible enumerar 6 funciones prioritarias a resolver para comenzar a esbozar nuestro proyecto de producto turístico:

- Permite al turista participar en la actividad principal del viaje.

- Además de ser partícipe de la actividad principal, facilita vivir la experiencia total del viaje como el turista quiere.

- Facilita el transporte hacia y desde el destino, así como dentro del propio destino.

- Favorece la interacción social del turista durante el viaje.

- Ayuda y simplifica la preparación y gestión del viaje.

- Facilita al turista recordar y revivir el viaje, compartir dicho viaje y experiencia con otras personas.

Las nuevas exigencias sociales, económicas y ambientales hacen necesario el diseño de productos turísticos donde la comunidad local sea considerada como el pilar fundamental para su creación y desarrollo (Ramírez, 2019).

\section{d. Los itinerarios como producto turístico}

El itinerario turístico se define como un recorrido, realizado por medios de transporte, hacia diversos atractivos turísticos (naturales, históricos, urbanos, antrópicos, entre otros), con paradas de interés histórico el cual busca satisfacer las necesidades turistas (Yepes Piqueras, 2016).

La aparición de nuevos productos turísticos basados en rutas o itinerarios turísticos supone la aplicación de estrategias que puedan favorecer la diferenciación respecto a los destinos competidores (Arce et al., 2020).

El itinerario cultural posee una específica dinámica y funcionalidad histórica al servicio de un fin concreto y determinado, que reúna las siguientes condiciones:

- Ser resultado y reflejo de movimientos interactivos de personas, así como de intercambios multidimensionales, continuos y recíprocos de bienes, ideas, conocimientos y valores entre pueblos, países, regiones $\mathrm{o}$ continentes.

- Haber generado una fecundación múltiple y recíproca, en el espacio y en el tiempo, de las culturas afectadas que se manifiesta tanto en su patrimonio tangible como intangible.

- Haber integrado en un sistema dinámico las relaciones históricas y los bienes culturales asociados a su existencia. Consejo Internacional de Monumentos y Sitios (ICOMOS, 2008). 
Este organismo diferencia conceptualmente los itinerarios culturales de las rutas turísticas, incluso de las que tienen interés cultural.

\section{a. Atractivos turísticos históricos de la Isla San Cristóbal}

Como parte del patrimonio cultural tangible e intangible de las islas, debemos citar hechos históricos como el inicio de la colonización en el año 1866 cuando el ecuatoriano Manuel J. Cobos, a bordo de dos embarcaciones llamadas Julián y Josefina Cobos desembarcó en Bahía Naufragio con un grupo de 10 trabajadores para iniciar la instalación de un ingenio azucarero al que le denominó la "Hacienda El Progreso", empresa que, durante 25 años, desde 1879 hasta 1904 fue el motor económico de la isla. Las ruinas se encuentran situadas en la entrada del poblado del mismo nombre. Y, la creación de la sociedad pesquera "La Predial" que durante los años 1952 a 1960 pretendió desarrollar la pesca a escala industrial (Gad Municipal San Cristóbal, 2015).

Si tú le dices a un extranjero, que se está comprando un boleto para ir a ver a Darwin y a las tortugas, que en Galápagos hace 200 años hubo un ingenio azucarero, te va a decir que no es posible. (Delgado, 2020)

Hace aproximadamente 160 años, las Islas Galápagos fueron testigos de la increíble historia de Manuel Julián Cobos, el hombre que, a través de medios cuestionables logró hazañas muy adelantadas a su tiempo.

Cobos, frecuentemente descrito como un hombre incansable, tenaz y seguro de sí mismo, llega a la Isla San Cristóbal en su misión de explotar un famoso tipo de líquen llamado orchilla, ampliamente utilizado en la industria tintorera aun cuando se creía que dicha isla era un terreno "inútil" e infértil e incluso, pudo diseñar y construir su enorme hacienda en un terreno que cualquiera hubiera considerado no apto para la construcción, y lo hizo todo con sus propias manos. 
Figura 2

Propuesta de Itinerario 1

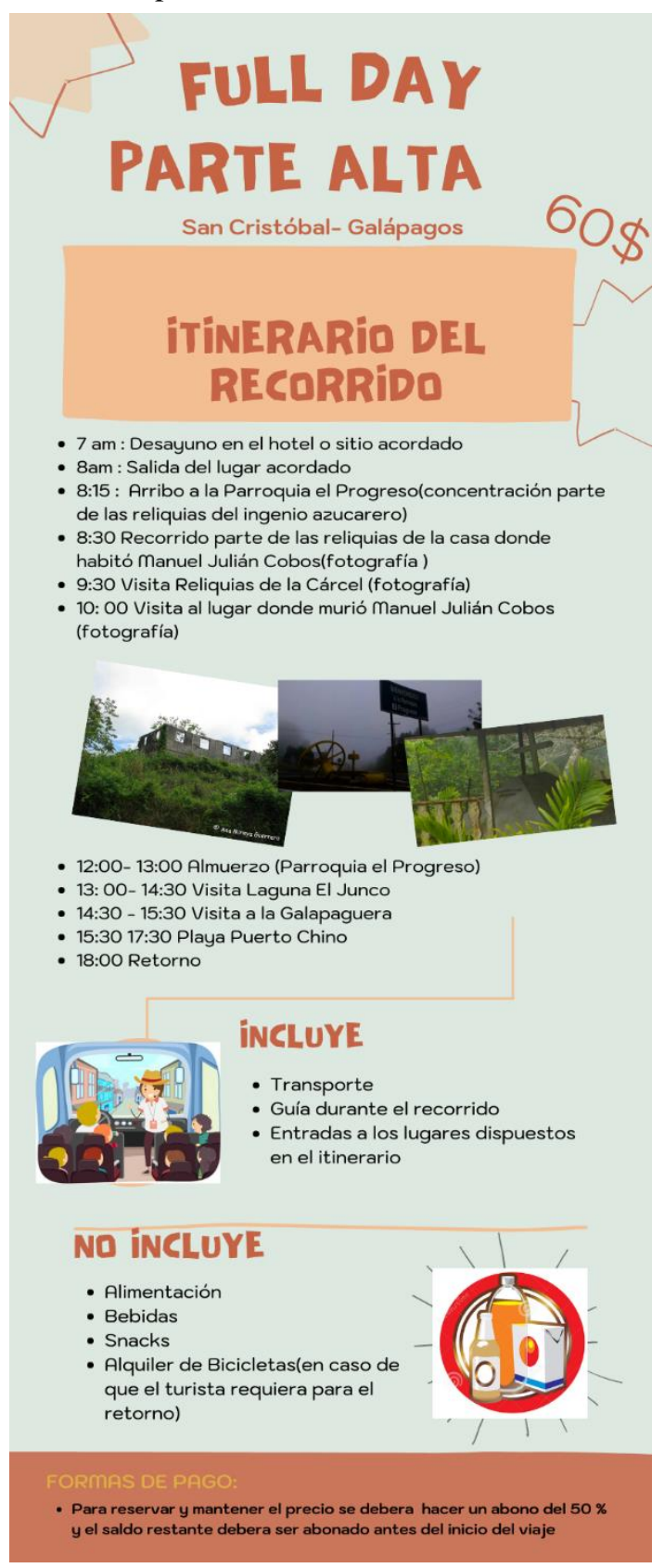

Figura 3

Propuesta de Itinerario 2

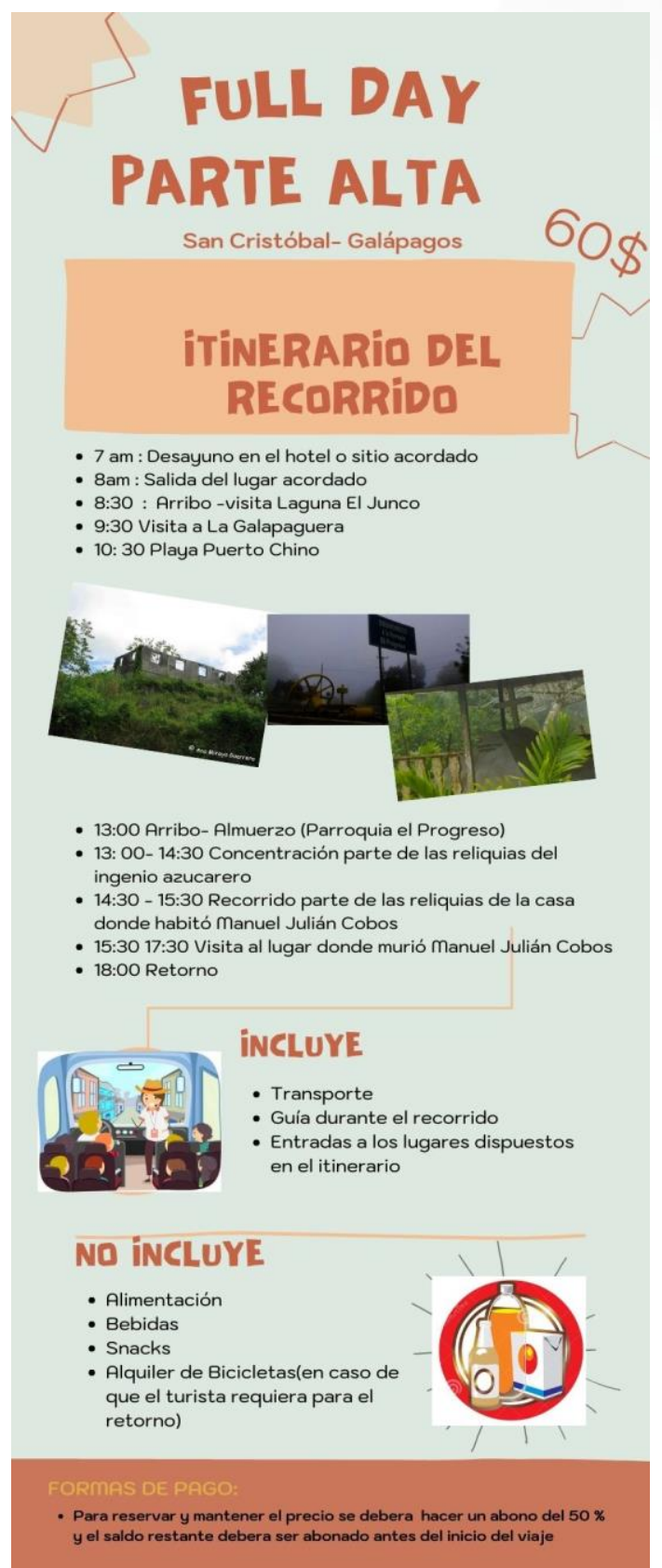

Cobos incluso descubriría fuentes de agua dulce un volcán de la Isla San Cristóbal y, así su fuerte temple lo llevó a trabajar la salvaje tierra por alrededor de diez años. Cobos pudo desarrollar dicha actividad hasta que nuevos tintes sintéticos llegados desde Europa convirtieran al negocio de las tintas en uno poco rentable.

No obstante, esto no desanimaría la insaciable hambre de Cobos por emprender y ser un gran terrateniente. A partir de allí, el ambicioso hombre querría probar suerte en el 
negocio de las mieles y para ello, necesitaba trabajadores. Desde Guayaquil, se dice que Cobos trajo a varios hombres a las Islas con el objetivo de que trabajaran para él en calidad de campesinos, como era la costumbre en ese entonces. Sin embargo, las versiones que posteriormente pudieron contar quienes trabajaron, o que sobrevivieron, a él, dejan en duda si aquellas personas trabajaron con él de manera voluntaria o si se mantuvieron allí en contra de su voluntad, en calidad de esclavos (Loaiza, 2021).

Esa obra, ubicada en la parte alta de la isla San Cristóbal, ha intentado ser rescatada por los pobladores del lugar, funcionarios locales, universidades nacionales y extranjeras, pero el legado de Cobos permanece desconocido para muchos ecuatorianos y la gran mayoría de extranjeros.

Lo que atrae a Cobos a las Galápagos, más precisamente a la isla de San Cristóbal, fue la explotación de orchilla, un líquen utilizado en la industria tintorera, esto ocurrió en 1866, 42 años después de que Ecuador se hiciera cargo de las islas y en medio de ingentes esfuerzos del gobierno ecuatoriano por colonizarlas.

En 1880, luego de pasar 10 años explotando este liquen en Baja California, Cobos regresa a San Cristóbal a buscar nuevas oportunidades, ya que el negocio de la orchilla había sido afectado por el progreso de las anilinas europeas.

En la isla, Cobos comienza la preparación del terreno para plantar caña de azúcar para la confección de mieles, panela y aguardiente. En Guayaquil, su socio José Monroy comercializa los productos y consigue trabajadores para el ingenio, según Latorre (2020):

Es difícil conocer cuántos trabajadores eran 'forzados' y cuántos 'conciertos' o voluntarios, pues nunca se hizo diferencia en la hacienda ni se tenía trato especial en la isla. Una vez llegados allá, todos estaban sujetos a la misma regla, la misma comida y a los mismos castigos.

Los castigos no eran tan comunes porque toda la población de la isla dependía completamente de la voluntad de Cobos, tanto en comida y agua, como en vivienda y transporte. El dueño del ingenio incluso creó su propia moneda (Zibell, 2020). 


\section{Resultados}

Tabla 3

Atractivos Turísticos Tangibles

Ruinas de Casa de Manuel Julián Cobos y su familia

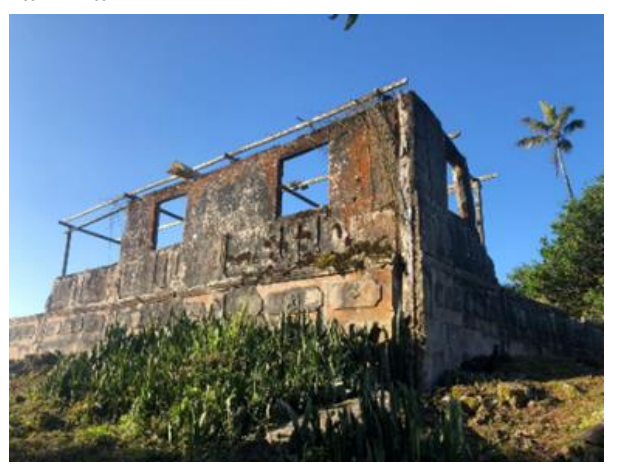

Nota: El gráfico representa parte de la vivienda principal donde habitó Manuel Julián Cobos y su familia (La British Broadcasting Corporation [BBC], 2020).

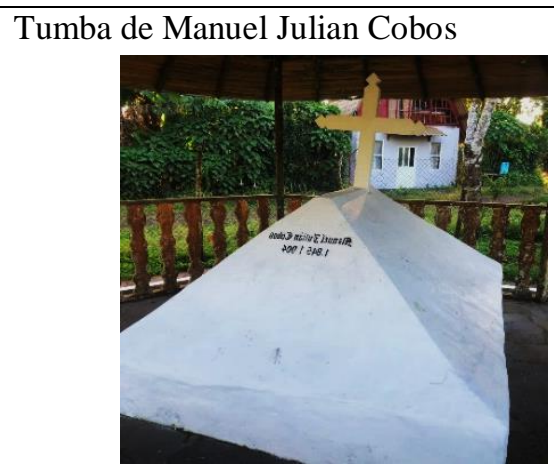

Nota: El gráfico representa el lugar referencial donde fue asesinado Manuel Julián Cobos por sus propios trabajadores (Maldonado \& Llerena, 2019).
Reliquias de Ingenio azucarero de Manuel J Cobos

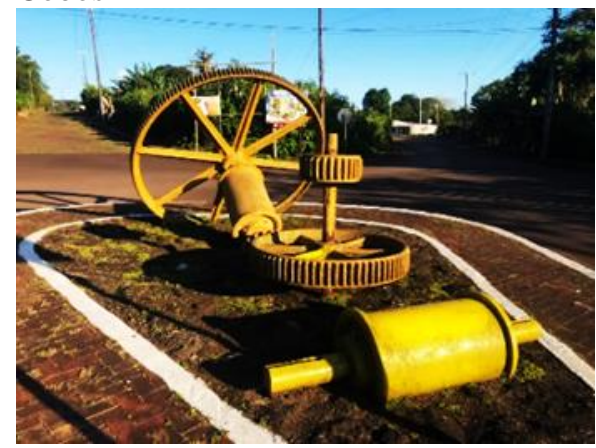

Nota. El gráfico representa parte de las maquinarias utilizadas para la producción de un promedio anual de 500 toneladas de azúcar que fueron transportadas al continente, entre 1879 y 1904 (Ministerio de Cultura y Patrimonio, 2017).

Casa común construida por obreros.

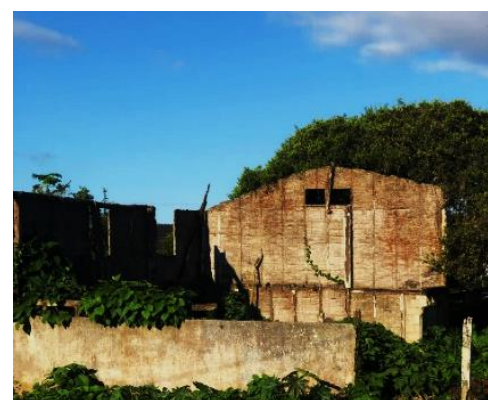

Nota: El gráfico representa una vivienda referencial de trabajadores de aquella época 1870 aproximadamente (Guerrero Gutiérrez, 2010).

\section{Nota: Ruinas de la Hacienda El Progreso 1866-1904}

Una vez que se cumplió la metodología para el desarrollo de la investigación de los atractivos turísticos a partir del análisis del turismo histórico - San Cristóbal, Islas Galápagos - Ecuador, tenemos como resultado cuatro puntos geográficos, que son de relevancia debido al contexto historia que representa para la localidad, se indica en la tabla 3 . 
Los atractivos turísticos históricos indicados anteriormente no se encuentran en condiciones óptimas debido a las condiciones ambientales de la isla y al deterioro de la infraestructura por el pasar de los años; como se observa en la tabla 3 existen cuatro atractivos turísticos históricos que son: i) Casa Manuel Julián Cobos, (ii) Reliquias del Ingenio Manuel J. Cobos, (iii) Casa de los Trabajadores, (iv) Tumba de Manuel J. Cobos, dichos recursos turísticos necesitan la intervención de los organismos y personas que corresponda para que se mejore, cuide, fortalezca y sobre todo que se conserve el patrimonio cultural de la isla, considerando la posibilidad de que sea un ingreso ingresos económicos adicional para los habitantes de la localidad.

\section{Piezas arqueológicas}

\section{Tabla 4}

Piezas Arqueológicas I

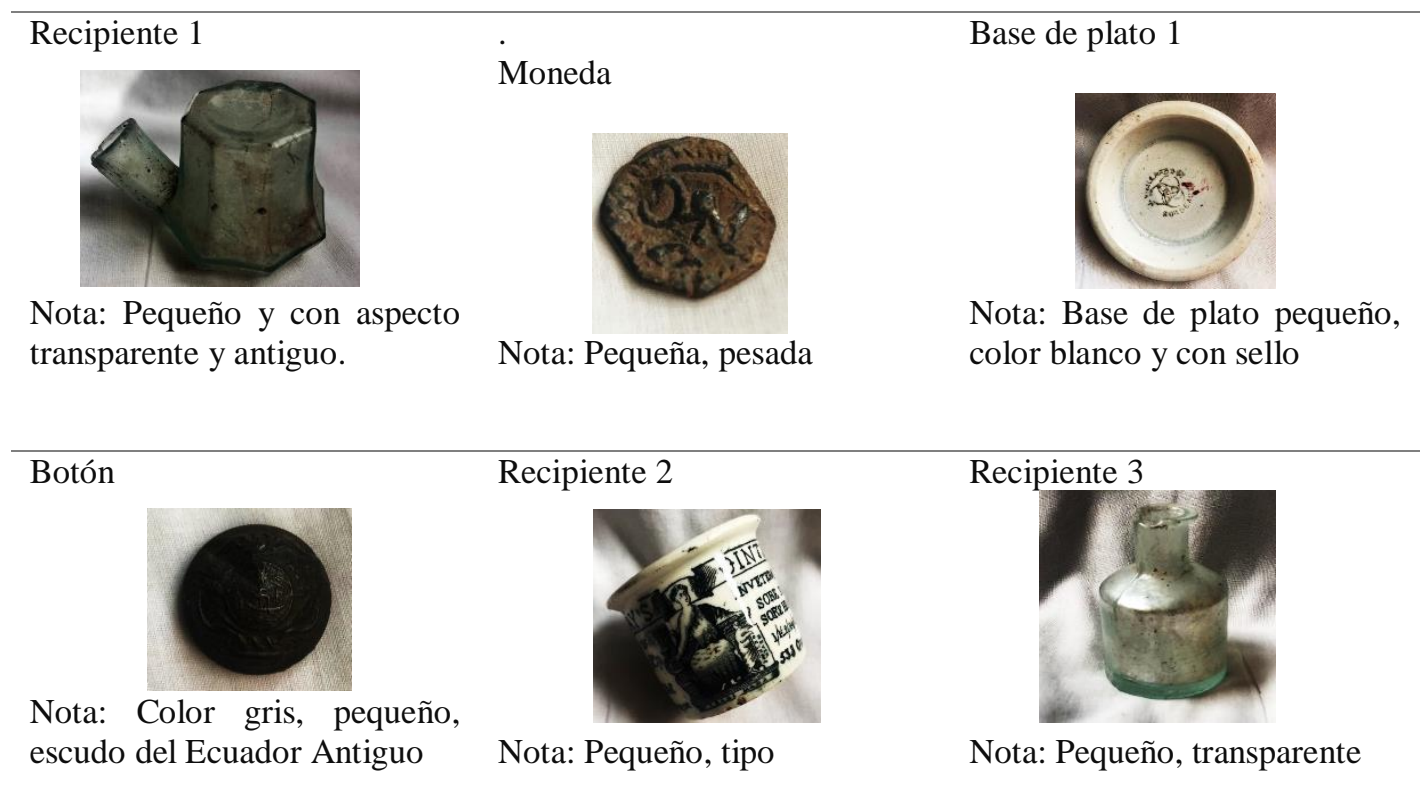

Nota: Piezas Arqueológicas localizas en la propiedad privada de la Familia Liviapoma Álvarez, Parroquia El Progreso, San Cristóbal, Galápagos. 


\section{DDigital}

\section{Tabla 5}

\section{Piezas Arqueológicas II}

Base de plato 2

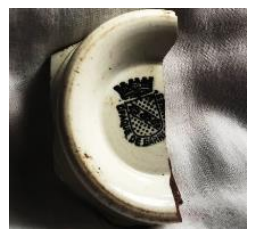

Nota: Porcelana, Sello Francés
Nota: Blanco y negro,

Marmoleado, Estilo vintage, Tipo florero, Grande.
Recipiente 4

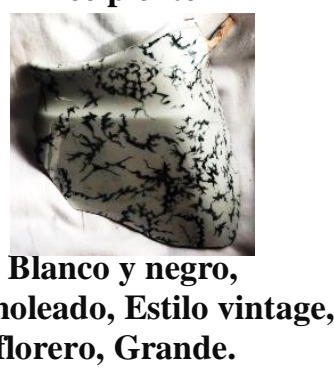

Recipiente 5

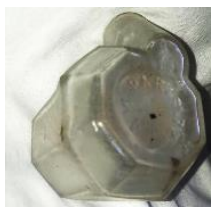

Nota: Pequeño, transparente
Plato

Nota:

blanco

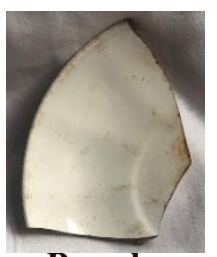

color
Botella 1

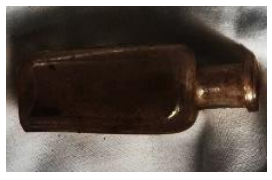

Nota: De color café, pequeño
Recipiente 7

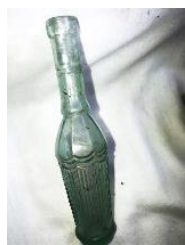

Nota: Alargado, pequeño, transparente
Botella 2

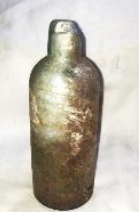

Nota: Mediana, transparente

Recipiente 8

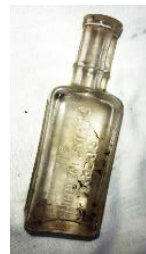

Nota: Recipiente de aceite de máquina de coser de esperma.
Nota: Pequeño, transparente

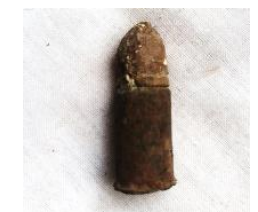

Nota: Pequeña, oxidada

Bala 1

\section{Bala 2}

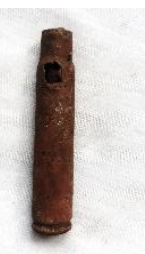

Nota: Pequeña, alargada

\section{Bala 3}

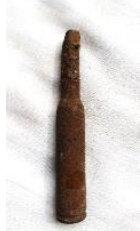

Nota: Pequeña, alargada

Nota: Piezas Arqueológicas localizas en la propiedad privada de la Familia Liviapoma Álvarez Parroquia El Progreso, San Cristóbal, Galápagos. 
Como resultado adicional de la búsqueda de los atractivos turísticos históricos, se encontraron piezas arqueológicas únicas en una propiedad privada de la Familia Liviapoma Álvarez, en las tablas 4 y 5 se observan alrededor de dieciocho piezas arqueológicas con características únicas, la propiedad pertenece a la parroquia El Progreso, San Cristóbal Galápagos.

Como se muestra en las tablas 4 y 5 estas piezas arqueológicas son: ocho recipientes, una moneda, dos bases de plato, un botón, un plato, dos botellas y finalmente tres balas; estas piezas antiguas es el inicio para realizar un estudio arqueológico más profundo.

\section{Conclusiones}

- La Parroquia El Progreso del Cantón San Cristóbal de las Islas Galápagos por su ubicación geográfica es un sitio de gran interés turístico histórico, existen materiales arqueológicos suficientes para convertirlos en recreaciones turísticas, para la visita de residentes de las islas, más aún de visitantes nacionales y extranjeros; además geográficamente el territorio posee gran potencial por sus atractivos turísticos, de igual forma por caracterizarse para la recreación y desarrollo de actividades turísticas; la preservación de la naturaleza, el manejo adecuado de las piezas arqueológicas ayudaría a promover, conocer, revalorar y fortalecer la identidad local de sus habitantes.

- Se ha identificado los siguientes atractivos turístico-históricos siendo cuatro los más relevantes indicados en la tabla 3: (i) Casa Manuel Julián Cobos, (ii) Reliquias del Ingenio Manuel J. Cobos, (iii) Casa de los Trabajadores, (iv) Tumba de Manuel J. Cobos, por tal razón en estos se debe de realizar intervenciones técnicas que permita si conservación de manera sustentable antes de que se deterioren o pierdan por completo.

- En la propiedad de la Familia Liviapoma se encontraron dieciocho piezas arqueológicas compuestas por: ocho recipientes, una moneda, dos bases de plato, un botón, un plato, dos botellas y finalmente tres balas, las figuras y mayor descripción se encuentran en las tablas 4 y 5 .

- Debido al gran potencial turístico de las islas se definieron actividades y rutas turísticas que se podrían realizar en un máximo de 24 horas las figuras 2 y 3 hacen un resumen de las actividades para conocer la historia de San Cristóbal; estos afiches pueden ayudar a incrementar la motivación de viaje a turistas nacionales o extranjeros. 


\section{Referencias bibliográficas}

Arce, F., Argudo, N., Suárez, E., \& Solís, V. (2020). Análisis de los productos turísticos: caso Península de Santa Elena, Ecuador. Revista UEES. Análisis de los productos turísticos: caso Península de Santa Elena, Ecuador

BBC. (2020). BBC News Arrival. https://www.bbc.com/mundo/noticias-51376490

Carvajal, V., \& Lemoine , A. (2017). Analysis of the tourist attractions and resources of Cantón San Vicente. Redalyc.

CEUPE. (2021). CEUPE Magazine. https://www.ceupe.com/blog/que-es-un-productoturistico.html

Delgado Espinoza, F. (2020). https://www.bbc.com/mundo/noticias-51376490

García Silberman, A. (2017). Capítulo 2. Clasificación de los atractivos turísticos. http://www.igeograf.unam.mx/Geodig/antologia/index.html/pdf/2_garcia.pdf

Gobierno Autónomo Descentralizado Municipal Gad Municipal San Cristóbal. (2015). http://www.sancristobalgalapagos.gob.ec/web/index.php/san-cristobal/2015-0406-15-01-20/resena-historica

Guerrero Gutiérrez, M. (2010). http://pinzonesygorriones.blogspot.com/2010/

ICOMOS. (2008). Consejo Internacional de Monumentos y Sitios. https://www.icomos.org/images/DOCUMENTS/Charters/culturalroutes_sp.pdf

Jared, J. (2015). Happygringo. https://happygringo.com/es/blog/san-christobal-islandgalapagos/

Latorre Tapia, Á. O. (2020). BBC News. https://www.bbc.com/mundo/noticias-51376490

Loaiza Ruiz, Y. (25 de septiembre de 2021). Infobae. https://www.infobae.com/america/america-latina/2021/09/25/quien-fue-manuelcobos-el-emperador-tiranico-de-galapagos/

Maldonado, R., \& L. E. (20 de diciembre de 2019). Historia Humana Isla San Cristóbal. http://www.galapagos.gob.ec/wp-content/uploads/downloads/2021/02/Historiahumana-San-Cristobal.pdf

Ministerio de Cultura y Patrimonio. (30 de junio de 2017). https://www.culturaypatrimonio.gob.ec/manuel-j-cobos-y-su-aporte-a-lacolonizacion-de-las-galapagos/ 
turismo.

(2018).

https://servicios.turismo.gob.ec/descargas/InventarioAtractivosTuristicos/MAN UAL-ATRACTIVOS-TURISTICOS.pdf

MINTUR. (2017). Ministerio de Turismo. https://servicios.turismo.gob.ec/descargas/InventarioAtractivosTuristicos/Parte1 _GuiaMetodologicaInventarioGeneracionEspacioTuristico2017_2daEd.pdf

MINTUR. (30 de mayo de 2019). https://www.turismo.gob.ec/documento-tecnicomuestra-la-dinamica-turistica-de-galapagos/

Morillo Moreno, M. (2010). Turismo y producto turístico. Evolución, conceptos componentes y clasificación. Redalyc, https://www.redalyc.org/pdf/4655/465545890011.pdf. http://scielo.sld.cu/scielo.php?script=sci_arttext\&pid=S230691552018000200007\&lng=es\&nrm=iso

Nasimba, C., \& Cejas, M. (2018). Diseño de productos turísticos y sus necesidades. Qualitas, 25. Obtenido de https://www.unibe.edu.ec/wpcontent/uploads/2017/08/2015-dic_NASIMBA-Y-CEJAS-DISE\%C3\%91O-DEPRODUCTOS-TUR\%C3\%8DSTICOS-Y-SUS-FACILIDADES.pdf

Ramírez Hernández, O. I. (septiembre de 2019). Scielo. http://scielo.senescyt.gob.ec/scielo.php?script=sci_arttext\&pid=S139086182019000100127

Yepes Piqueras, V. (22 de Julio de 2016). Universidad Politécnica de Valencia. https://victoryepes.blogs.upv.es/2016/09/14/los-itinerarios-tematicos-comoelementos-diferenciadores-del-producto-turistico-global/

Zibell García, M. (23 de febrero de 2020). BBC News mundo. https://www.bbc.com/mundo/noticias-51376490

\section{$\lfloor$ Ciencia}


El artículo que se publica es de exclusiva responsabilidad de los autores y no necesariamente reflejan el pensamiento de la Revista Conciencia Digital.

\section{Ciencia \\ LDigital}

El artículo queda en propiedad de la revista y, por tanto, su publicación parcial y/o total en otro medio tiene que ser autorizado por el director de la Revista Conciencia Digital.
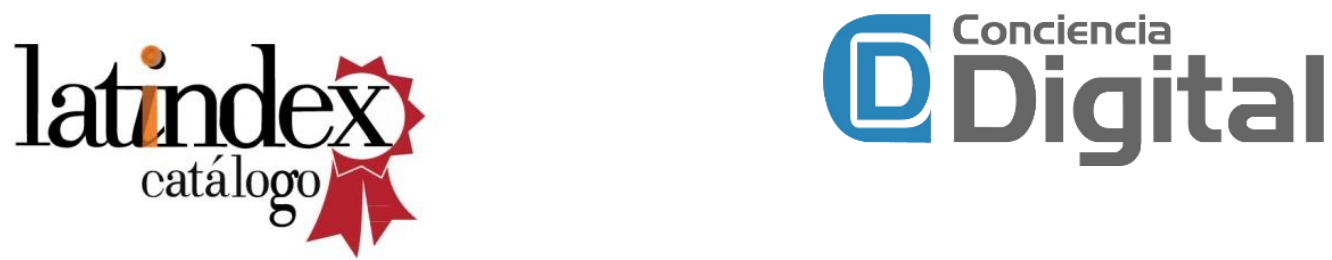

Indexaciones

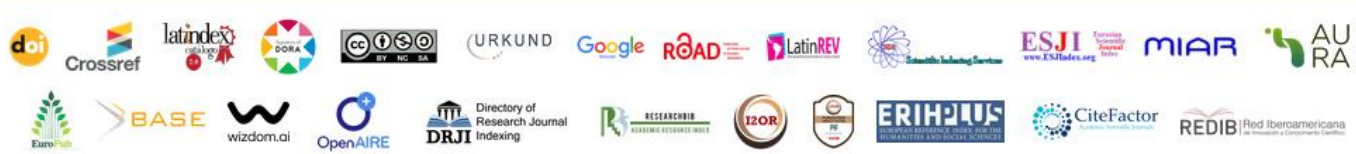

